\title{
Novel roles of the autocrine motility factor/phosphoglucose isomerase in tumor malignancy
}

\author{
$T$ Yanagawa, T Funasaka, S Tsutsumi ${ }^{1}, H$ Watanabe ${ }^{2}$ and $A$ Raz
}

\author{
Tumor Progression and Metastasis, Karmanos Cancer Institute, Wayne State University, School of Medicine, Detroit, \\ Michigan 48201, USA \\ ${ }^{1}$ Department of General Surgical Science (Surgery I), Gunma University Graduate School of Medicine, Maebashi, 371-8511, \\ Japan \\ ${ }^{2}$ Department of Orthopedic Surgery, Gunma University Graduate School of Medicine, Maebashi, 371-8511, Japan
}

(Requests for offprints should be addressed to A Raz, Tumor Progression and Metastasis, Karmanos Cancer Institute, 110 East Warren Avenue, Detroit, Michigan 48201, USA; Email: raza@karmanos.org.)

\begin{abstract}
Autocrine motility factor (AMF) stimulates cell motility in an autocrine manner and is related to tumor malignancy. AMF is a multifunctional molecule, also known as phosphoglucose isomerase and neuroleukin. Signal cascades of the AMF-stimulated motility and novel functions of this protein contributing to tumor malignancy have been presented recently. AMF stimulation activated small Rholike GTPases and subsequently induced actin fiber rearrangement, which was removed by the C3 exoenzyme, a specific inhibitor of Rho. The expression of Jun N-terminal kinase (JNK)1, JNK2 and the Rho GDP dissociation inhibitor- $\beta$ was upregulated by AMF. The addition of AMF to culture medium stimulated the motility of the endothelial cells and the formation of tube-like structures in collagen gels. Highly AMF-expressing HT1080 cells induced aggressive angiogenesis in vivo. The expression of fmslike tyrosine kinase (Flt)-1, a vascular endothelial growth factor (VEGF) receptor, was enhanced in AMF-expressing tumors dependent on protein kinase $C$ and phosphatidylinositol 3 kinase (PI3K) activation; meanwhile kinase insert domain-containing receptor, another receptor of VEGF, was not. Permeability of mesothelial and endothelial cell monolayers was increased by AMF, and numerous gaps were observed in the monolayers after treatment with AMF. AMF gene transfection transformed NIH3T3 cells to proliferate quickly and acquire anti-apoptosis ability induced by serum deprivation in a PI3K-dependent manner. The anti-apoptotic effect of AMF has been described by other authors who have shown that the AMF over-expressing cells were resistant to mitomycin-C-induced apoptosis showing regression of Apaf- 1 and caspase-9 dependent on PI3K and MAP kinase. These novel functions of AMF makes it a likely target for cancer therapy.
\end{abstract}

Endocrine-Related Cancer (2004) 11 749-759

\section{Introduction}

Autocrine motility factor (AMF) was originally purified from the conditioned medium of human A2058 melanoma cells as a $55 \mathrm{kDa}$ cytokine that stimulates the random or directed motility of cells in an autocrine manner (Liotta et al. 1986). This protein is elevated in the serum or urine of patients with malignant tumors such as gastrointestinal, kidney, breast, colorectal and lung carcinomas, thereby being useful as a tumor marker (Baumann \& Brand 1988, Baumann et al. 1990, Filella et al. 1991, Patel et al. 1995).

Molecular cloning and sequencing have identified AMF as a phosphoglucose isomerase (PGI) (Watanabe et al. 1996), neuroleukin (NLK) (Chaput et al. 1988, Faik et al. 1988) and maturation factor (MF) (Xu et al. 1996), suggesting that this cytokine is multifunctional and a member of the ectoenzyme/exoenzyme family. PGI is an ubiquitous cytosolic enzyme that plays a critical role in both Embden-Meyerhof glycolytic and glucogenetic pathways, catalyzing the reversible interconversion of glucose-6-phosphate to fructose-6-phosphate (Harrison 1974). Specific PGI inhibitors inhibit not only PGI activity but also suppress the cell motility stimulated by AMF (Watanabe et al. 1996). Crystal structure analysis and site-directed mutagenesis studies 
have revealed that the regions responsible for PGI enzymatic activity overlap AMF cytokine active sites (Tanaka et al. 2002). Since hereditary non-spherocytic hemolytic anemia associated with PGI deficiency was first reported in 1968 (Baughan et al. 1968), this anemia has been found in many patients with PGI mutations, which are not, however, common (Kanno et al. 1996, Beutler et al. 1997). NLK is a neurotrophic factor that supports the survival but not the proliferation of embryonic spinal and sensory neurons, but it does not affect sympathetic or parasympathetic neurons (Gurney et al. 1986a). The expression of NLK and its receptor is increased in the hippocampus of rats when maze learning and is reduced in aged rats with learning deficits (Luo et al. 2002). A point mutation of NLK is associated with mental retardation (Schröter et al. 1985, Kugler et al. 1998). MF mediates the differentiation of human myeloid leukemia HL-60 cells to terminal monocytic cells (Xu et al. 1996). Furthermore, this protein can induce immunoglobulin secretion by cultured human peripheral blood mononuclear cells (Gurney et al. 1986b), affect the differentiation of osteoblastic mouse cell MC3T3-E1 (Zhi et al. 2001) and is defined as the antigen that provokes arthritis of the $\mathrm{K} / \mathrm{BxN} \mathrm{T}$ cell receptor transgenic mouse with many features similar to rheumatoid arthritis in humans (Matsumoto et al. 1999).

Interestingly, AMF has no signal peptide essential for the classical or endoplasmic reticulum (ER)/Golgidependent secretary pathway and is predominantly secreted from some kinds of tumor cells (Liotta et al. 1986, Silletti et al. 1991, Watanabe et al. 1991a, Watanabe 1994, Niinaka et al. 1998) or $\mathrm{T}$ cells stimulated with lectins such as Concanavalin A, phytohemagglutinin or pokeweed mitogen (Gurney et al. 1986b). We have reported that the transfection of the AMF gene into normal or non-AMF-secreting tumor cells augments the release of AMF (Tsutsumi et al. 2003, Yanagawa et al. 2004). In addition, the cells secreting AMF express higher mRNA levels of AMF than do normal cells (Niinaka et al. 1998), and secreted AMF is phosphorylated (Haga et al. 2000). Phosphorylation or an excess amount of this protein in the cytosol may induce secretion of AMF although the details of the secretion mechanism still remain uncertain.

Secreted AMF stimulates cell motility via binding to a seven transmembrane glycoprotein of $78 \mathrm{kDa}$, AMF receptor (AMFR)/gp78 (Silleti et al. 1991, Shimizu et al. 1999). AMFR was found on the surface of B16-F1 melanoma cells cultured as spheroids on a non-adhesive substrate (Nabi \& Raz 1987) and, recently, has been identified as a really interesting new gene (RING) fingerdependent ubiquitin protein ligase (E3) of the ER (Fang et al. 2001). This binding reaction is followed by internalization of the receptor, stimulating pertussis toxin (PT)sensitive G protein (Watanabe et al. 1991b), inositol phosphate production (Kohn et al. 1990) and receptor phosphorylation (Watanabe et al. 1991a). Analysis using specific kinase inhibitors has revealed that AMF-induced cell motility is dependent on protein kinase $\mathrm{C}(\mathrm{PKC})$ and tyrosine kinase, but not protein kinase A (PKA) (Timar et al. 1993, Kanbe et al. 1994). AMFR internalizes its ligand via two pathways, a caveolae-mediated pathway to the smooth ER tubules (Benlimame et al. 1998) and a clathrindependent pathway where the AMF/AMFR complex is delivered to the multivesicular body and AMF recycles to cell surface fibronectin fibrils (Le et al. 2000).

In addition to the facts mentioned above, some novel and important functions of AMF that contribute to tumor malignancy have been found recently. We describe their mechanisms and the relationship between AMF and the molecules related to motility, angiogenesis and antiapoptosis.

\section{The small Rho-like GTPases related to the motility induced by AMF}

The family of small Rho-like GTPases is critical for mediating a number of cellular processes such as proliferation, secretion and an extensive reorganization of the cytoskeleton, alterations of which are associated with a migratory phenotype (Ridley et al. 1992, Hall 1998, 1990). We therefore examined the roles of small Rho-like GTPases, RhoA, Racl and cdc42, in the cell motility stimulated by AMF (Tsutsumi et al. 2002). The levels of active RhoA, Racl and cdc42 in AMF-stimulated versus resting human malignant melanoma A375 cells were analyzed. AMF stimulation increased active RhoA and Rac1 levels in a time- and dose-dependent manner without elevation of total RhoA and Racl protein levels; meanwhile, active cdc42 levels did not change with AMF stimulation. Furthermore, responding to AMF stimulation, both Jun-N-terminal kinase (JNK)1 and JNK2 which are downstream proteins of small Rho-like GTPases were also increased in a dose-dependent manner.

Rho is essential for both the formation and maintenance of actin stress fiber (Ridley \& Hall 1992, Nobes \& Hall 1995). We have analyzed the distribution and organization of the molecules using immunofluorescence (Tsutsumi et al. 2002). AMF added to the conditioned medium effectively enhanced the motility of cells and reorganization of the actin molecules of A375 melanoma cells. This cytoskeletal rearrangement, the formation of heavy bundles of stress fiber-like structures transversing the cells, was also observed in human fibrosarcoma HT1080 cells stimulated by AMF. Next, we observed 


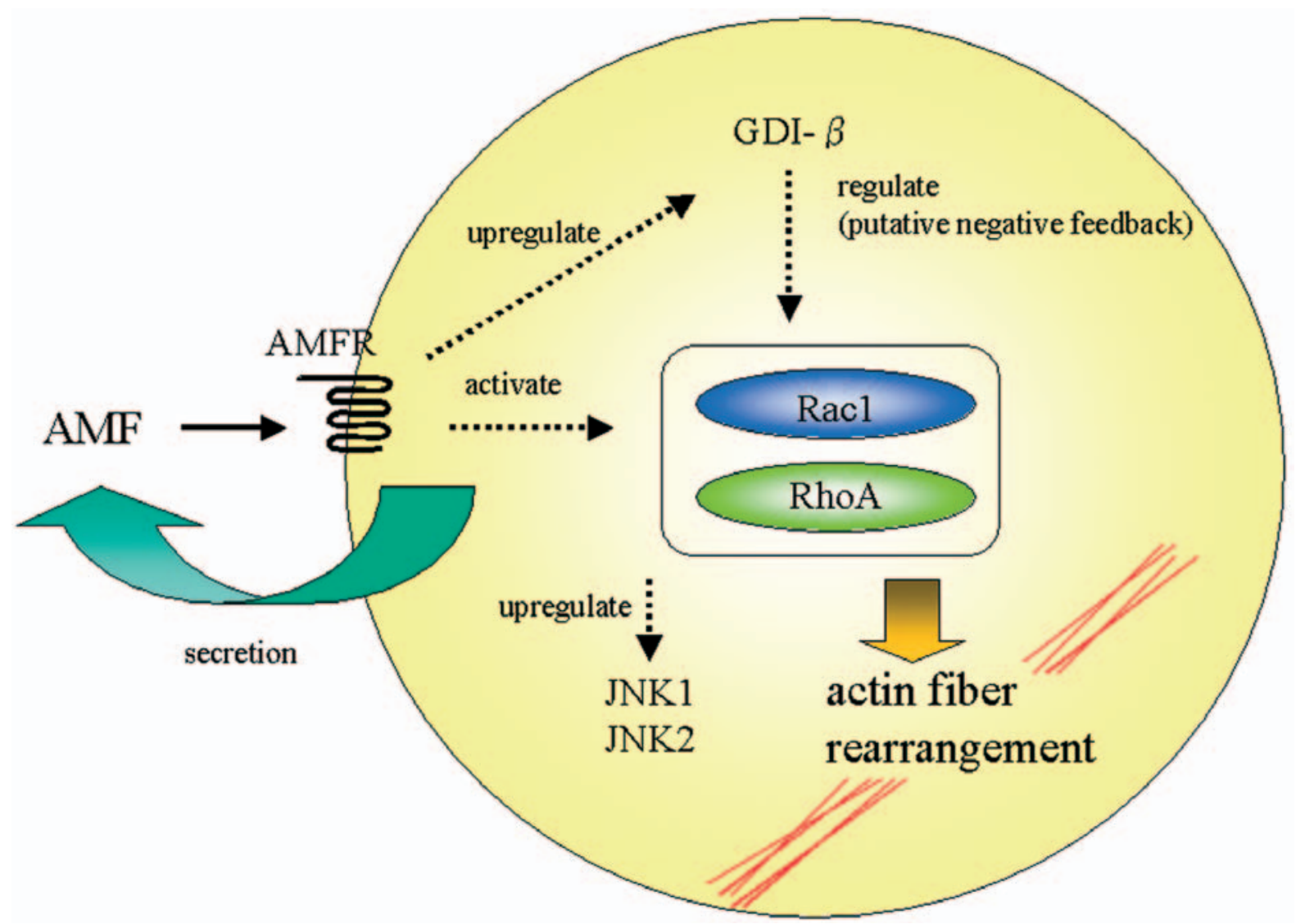

Figure 1 Signals of the molecules related to the motility induced by AMF stimulation. The motility of some tumor cells is enhanced by AMF. AMF stimulation via its receptor AMFR activates small Rho-like GTPase, Rac1 and RhoA in a time- and dose-dependent manner in human malignant melanoma A375 cells; meanwhile, cdc42 does not respond to AMF. Subsequent signals upregulate JNK1 and JNK2, both of which are downstream proteins of small Rho-like GTPases and induce actin fiber rearrangement, the formation of heavy bundles of stress fiber-like structures transversing the cells. AMF overexpression also enhances GDI- $\beta$ expression which regulates small Rho-like GTPases in the putative negative feedback mechanisms against excess signals from AMF.

the cytoskeletal changes induced by AMF in the presence of the C3 exoenzyme, a specific inhibitor of Rho. C3 exoenzyme inhibited stress fiber formation accompanied by a decrease in active RhoA, indicating that AMFinduced cytoskeletal rearrangement is dependent on Rho activation. Torimura et al. (2001) also demonstrated that, in human hepatoma cell lines, AMF/PGI enhanced Rho activity, which was slightly blocked by the functionblocking antibody for the integrin- $\beta 1$ subunit.

We recently presented evidence that overexpression of AMF in mouse fibrosarcoma Gc-4 PF cells using the adenovirus vector enhances the expression of Rho GDP dissociation inhibitor- $\beta$ (GDI- $\beta$ ) (Yanagawa et al. 2004). GDI- $\beta$, a member of the Rho GDI superfamily, regulates the small Rho family GTPases suppressing the GDP dissociation rate (Scherle et al. 1993, Dirac-Svejstrup et al. 1997). The role of GDI- $\beta$ in invasion and metastasis is still controversial. In ovarian carcinoma, upregulation of GDI- $\beta$ is associated with progression of the tumor (Tapper et al. 2001), while this protein is also reported as an invasion and metastasis suppressor in bladder cancers (Seraj et al. 2000, Gildea et al. 2002, Harding et al. 2002). Upregulation of GDI- $\beta$ might be induced as a negative signal in the putative feedback mechanisms against excess signals from AMF. Figure 1 represents the signals of the molecules related to the AMF-induced motility.

\section{The effect of AMF on endothelial cells}

Angiogenesis is a crucial process for tumor growth and metastasis (Liotta et al. 1974, Folkman et al. 1989) and has three main steps: enzymatic degradation of the basement membrane; endothelial cell migration; and 
endothelial cell multiplication. First, we focused on 'endothelial migration' and examined the effect of AMF on endothelial cells (Funasaka et al. 2001). For this experiment, we used human umbilical vein endothelial cells (HUVECs) and detected AMFR with immunofluorescence. The addition of AMF to the cells led to augmented expression of AMFR presumably caused by positive feedback. This phenomenon is observed in tumor cells (Niinaka et al. 1998). Phagokinetic assay revealed that the HUVECs' motility was increased approximately 2-fold by AMF stimulation. To accomplish the process of angiogenesis, migrating endothelial cells need to proliferate and undergo morphogenesis such as the formation of capillary-like tubes. AMF did not affect proliferation of HUVECs in vitro with the dose effective for motility stimulation. To investigate the changes in the structure formed by endothelial cells in vitro, we cultured HUVECs on collagen gels with or without AMF and measured the total length of a network of the cells elongated and anastomosed with each other. This tube-like structure, related to angiogenesis, was 2.5 -fold more in the culture with AMF than in that without AMF.

We used two ways to evaluate the in vivo angiogenic activity of AMF. The first one was the Matrigel plug assay according to the report by Passaniti et al. (1992). Matrigel in liquid form was mixed with/without AMF and injected subcutaneously into mice. AMF increased the cells infiltrating into the Matrigel that formed capillary-like tube structures in a dose-dependent manner. In another assay, the effect of AMF on tumor-induced angiogenesis was investigated using a diffusion chamber which contained HT1080 cells and which was transplanted into a mouse dorsal sac (Abe et al. 1993). We prepared two cell lines, HT1080 cells transfected with the AMF gene and a control counterpart. The cells transfected with the AMF gene secreted four-fold more than did the control cells. In addition, in this assay, AMF contributed to the formation of capillary blood vessels. We concluded that AMF is capable of affecting endothelial cells and inducing angiogenesis.

\section{The crosstalk between AMF-AMFR and vascular endothelial growth factor (VEGF)-VEGF receptor (VEGFR) signals}

Many angiogenic factors such as acidic-fibroblast growth factor (FGF), basic FGF, tumor necrosis factor (TNF)- $\alpha$, TGF- $\beta$ and VEGF are needed as either a stimulator or an inhibitor for the various steps in the angiogenesis process (Folkman \& Klagsbrun 1987, Folkman 1990, Folkman \& Shing 1992, Koch et al. 1992, Risau 1997). Among them, VEGF is the prime regulator of angiogenesis and affects endothelial cells specifically (Leung et al. 1989). VEGF acts via two tyrosine-phosphorylating receptors, fms-like tyrosine kinase (Flt-1) (Shibuya \& Yamaguchi 1990) and KDR (Terman et al. 1991), the expression of which is limited to the endothelium (de Vries et al. 1992, Quinn et al. 1993). We therefore proceeded to the next investigation, the signal crosstalk between VEGF-VEGFR and AMFAMFR (Funasaka et al. 2002). HT1080 cells known to secrete VEGF expressed more VEGF and AMFR at the mRNA level in the medium with AMF than in control medium. With regard to the VEGFRs, AMF increased the expression of Flt-1 in HUVECs in a dose-dependent manner while not that of KDR. To confirm the in vivo Flt-1 expression in response to tumor-secreted AMF, we implanted a diffusion chamber including HT1080 cells transfected with AMF into mice and evaluated the expression with immunohistochemical staining. Increased Flt-1 expression was found on the blood vessels surrounding the diffusion chamber.

Next, the biological function of the Flt-1 induced by AMF was examined. The HUVECs were exposed to AMF to enhance the Flt-1 expression and the motile response to VEGF of the pretreated cells was measured in three assays, the phagokinetic track assay (AlbrechtBuehler 1977), the wound healing assay (Silletti et al. 1993) and the Transwell migration assay (Repesh 1989). VEGF significantly stimulated the untreated cells' haptotactic and chemotactic motility but not the chemokinetic one as previously reported (Kumar et al. 1998). Meanwhile, the chemokinetic random locomotion of AMF-treated cells was also increased by VEGF in other motility assays. We considered that the augmented Flt-1 expression by AMF enhanced the sensitivity of endothelial cells to VEGF stimulation. This result is compatible with the fact that proliferative signals of VEGF in endothelial cells mainly depend on KDR, on the other hand, migrational activities depend on Flt-1 (Kanno et al. 2000, Soker et al. 2001).

Furthermore, the intracellular signal transduction of AMF-induced Flt-1 expression in HUVECs was investigated using various inhibitors, a non-isoform-selective PKC inhibitor GF109203X, a PKA inhibitor H89, a phosphatidylinositol 3 kinase (PI3K) inhibitor wortmanin, a MAP kinase (MAPK) inhibitor PD98059, a tyrosine kinase inhibitor genistein and a $G$ regulatory subunit of adenylate cyclase inhibitor PT. Among them, GF109203X and wortmanin could inhibit Flt-1 expression induced by AMF while the others had no suppressive effect, which indicated that AMF-induced Flt-1 expression in endothelial cells is dependent on the activation of PKC and PI3K in endothelial cells. Meanwhile, the AMF-AMFR pathway leading to tumor cell motility is regulated not only by PKC 


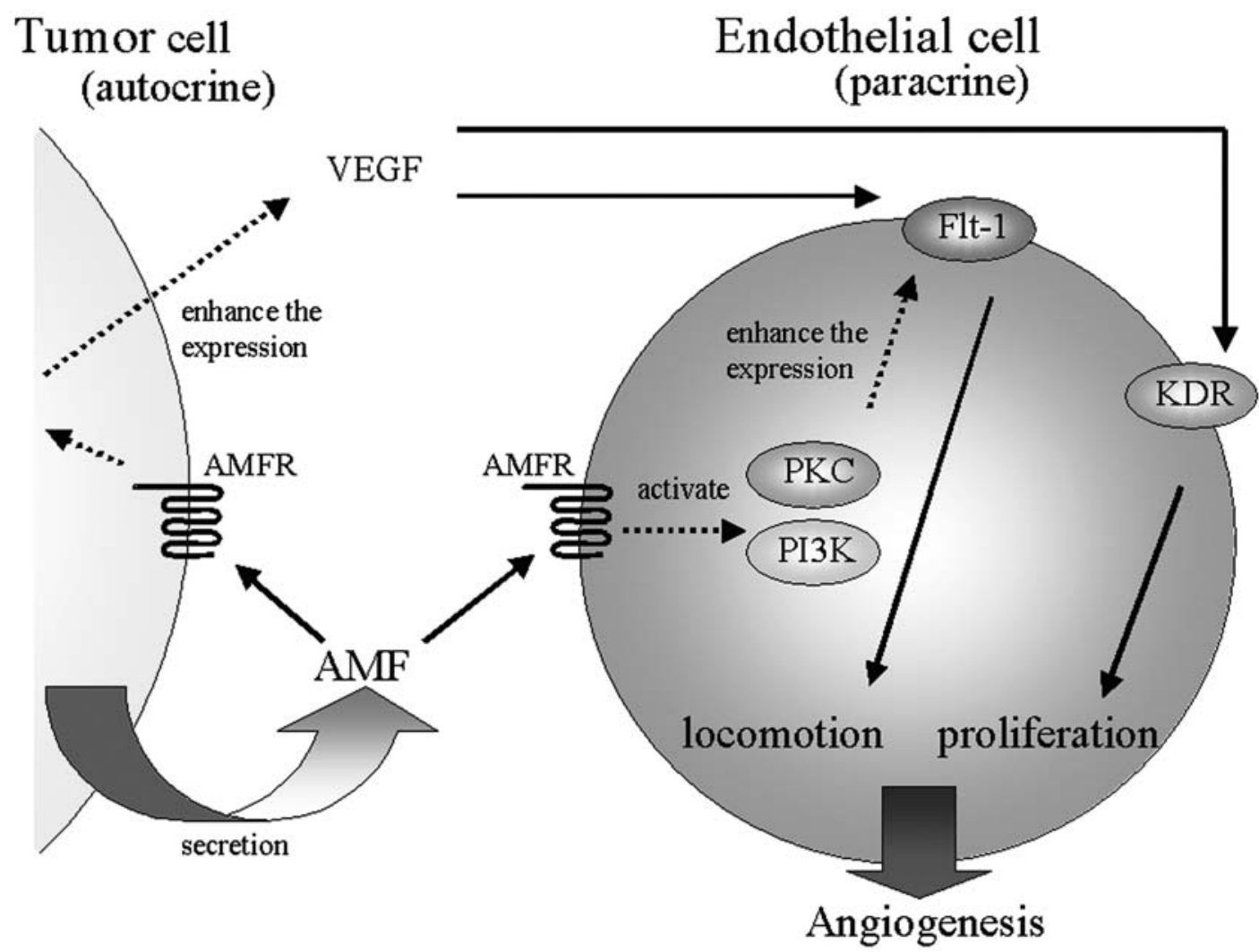

Figure 2 Interaction between AMF-AMFR and VEGF-VEGFR signal in the tumor and host endothelial cells. Secreted AMF stimulates tumor cells in an autocrine manner and enhances the production of VEGF which regulates endothelial cells via its receptor, Flt-1 and KDR. Host endothelial cells show augmented expression of Flt-1 responding to AMF stimulation in PKC- and PI3K-dependent manners. Increased Flt-1 contributes to endothelial locomotion responding to VEGF. In addition, AMF stimulation via AMFR also enhances endothelial cell motility. VEGF enhanced by AMF signals induces endothelial cell proliferation via KDR. These results indicated that AMF can change the sensitivity of endothelial cells to VEGF and induce angiogenesis in both autocrine and paracrine manners.

(Timer et al. 1993) but also by tyrosine kinase (Kanbe et al. 1994) and PT-sensitive G protein (Watanabe et al. 1991b). We present the interaction between AMFAMFR and VEGF-VEGFR signals in the tumor and host endothelial cells (Fig. 2).

\section{AMF involvement in the accumulation of ascites fluid}

Tumor ascites are produced due to various reasons such as lymphatic obstruction (Feldman et al. 1972), neovascularization of the parietal peritoneum (Garrison et al. 1987) and hyperpermeability of microvessels lining the peritoneal cavity (Senger et al. 1983, Garrison et al. 1987). The cellular morphological changes and movements are associated with the formation of cellular gaps in the endothelial monolayer which accelerates permeability (Maruo et al. 1992, Suarez \& Ballmer-Hofer 2001).
Thus we investigated the influence of AMF on the permeability of endothelial or mesothelial cells and ascites accumulation (Funasaka et al. 2002a). In the study, we used two types of Ehrlich mouse ascites tumor cell line, one of which grows well in mice and induces abundant ascites (Dunham \& Stewart 1953) and another which grows poorly and does not develop ascites (Boone et al. 1965). The former secreted AMF ten times more than the latter, which may suggest that AMF plays an important role in ascites accumulation. To examine the change in host cells by the AMF secreted from Ehrlich cells, we isolated mesothelial cells from a mouse (Akedo et al. 1986) and tested their motilities. Both recombinant AMF and a conditioned medium of Ehrlich cells stimulated mesothelial cell locomotion, which was inhibited by antiAMF antibody. The permeability of the mesothelial cell monolayer on micropore membranes was increased by the addition of recombinant AMF. The permeability of the 


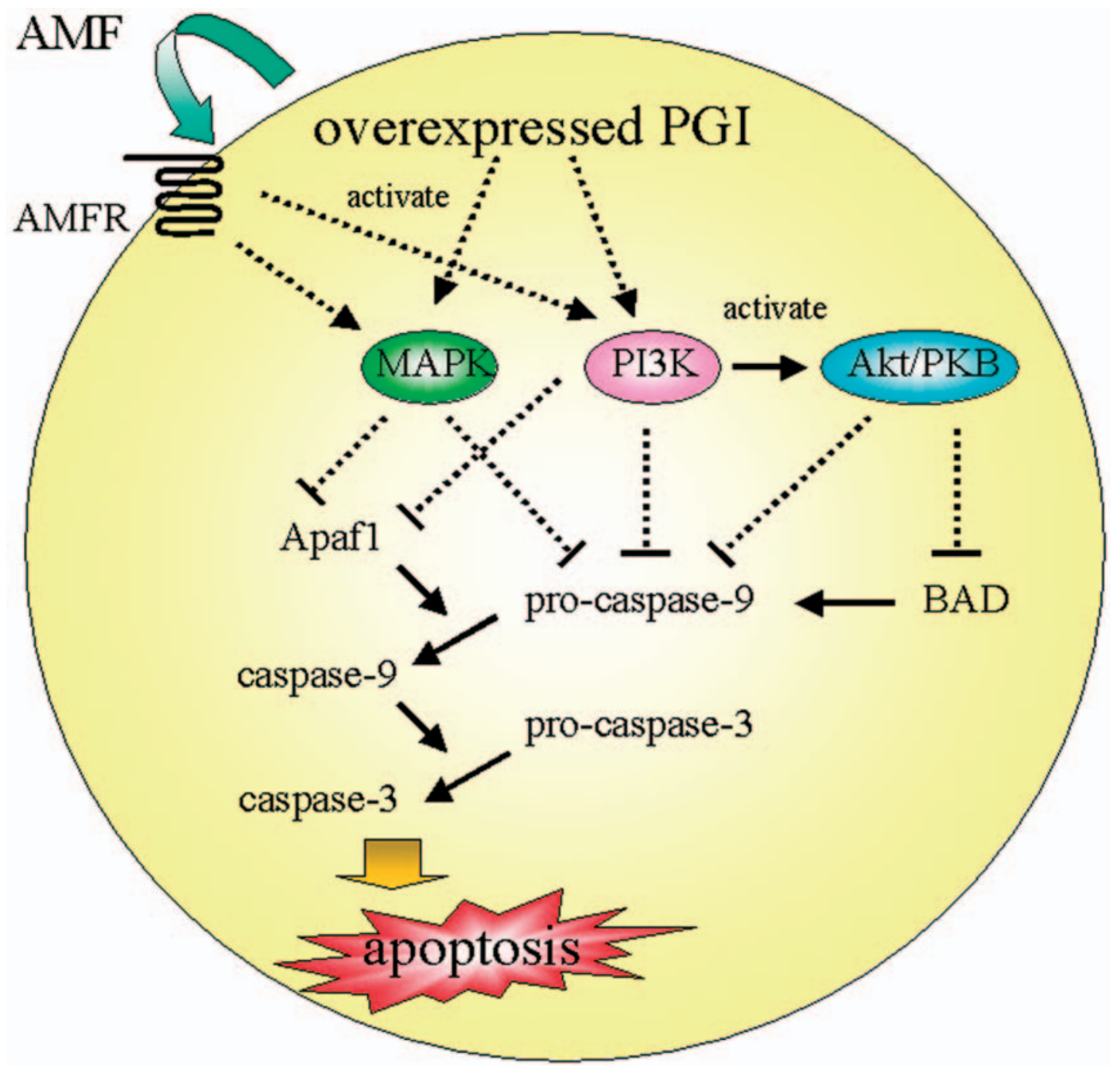

Figure 3 Signal pathways with regard to apoptosis resistance induced by AMF overexpression. AMF-expressing cells are resistant to apoptosis induced by serum deprivation or mitomycin-C. AMF signals activate PI3K which activates Akt/PKB, the signal of which inactivates BAD and caspase-9, thereby involving the suppression of apoptosis induced by serum deprivation. Another experiment shows AMF overexpression which suppresses the expression of Apaf- 1 and caspase- 9 which are important for apoptosis initiation, activating PI3K and MAPK and causing mitomycin-induced apoptosis resistance. There is a possibility that the increase of PGI enzymatic activity may cause hyper-metabolism of glucose which is related to malignant tumors and affects the apoptosis pathways.

HUVEC monolayer was also enhanced by AMF and the monolayer formed numerous gaps and was retracted. The enhancement of vascular permeability by AMF was also confirmed with the Miles' in vivo permeability assay (Miles \& Miles 1952). In addition, VEGF is known to increase microvessel permeability although its mechanism still remains to be defined (Dvorak et al. 1995, Luo et al. 1998). Taken together, these results indicated that AMF directly or indirectly enhances the permeability of endothelial and mesothelial layers and subsequently leads to accumulation of ascites.

\section{Anti-apoptotic effect related to AMF overexpression}

Many growth factors are known to transform normal cells and promote cell survival (Harrington et al. 1994, Bardelli et al. 1996, Bikfalvi et al. 1997, Parrizas et al. 1997, Descamps et al. 2001). We transfected the AMF gene into mouse fibroblast NIH3T3 cells and established the cell line overexpressing AMF (Tsutsumi et al. 2003). This cell line secreted AMF, although the parental or vector-only transfected control NIH3T3 cells did not, 
changed its morphology from a flat appearance to a fusiform one and acquired aggressive invading ability. Interestingly, the AMF-transfected cells inoculated into mice formed tumors whereas control cells failed to do so. In addition, the proliferation rate of the AMFtransfected cells was two-fold greater than that of the controls in vitro. Notably, these transfected cells were resistant to the induction of apoptosis evoked by serum deprivation which led the control cells to die. Thus, we examined the anti-apoptotic function of AMF using this cell line. To determine the apoptosis pathways affected by AMF overexpression, two pharmacological inhibitors, Ly294002 (PI3K inhibitor) and PD98059 (MAPK inhibitor) were used. DNA fragmentation, an indicator of apoptosis, was detected in AMF-transfected cells under treatment with Ly294002 but not with PD98059, which means that the AMF-induced apoptosis resistance is mainly dependent on PI3K. PI3K produces phosphoinositol phospholipid second messengers that activate Akt/protein kinase $\mathrm{B}$ (PKB) the signal of which phosphorylates the Bcl-2 family member BAD (Datta et al. 1997) and caspase-9 (Cardone et al. 1998) and is involved in apoptosis suppression (Franke et al. 1997, Khwaja et al. 1997). The activation of $\mathrm{Akt} / \mathrm{PKB}$ is provoked by phosphorylation of both Thr308 and Ser473 (Alessi et al. 1996). Western blot analysis using phosphospecific antibody against $\mathrm{Akt} / \mathrm{PKB}$ revealed that its phosphorylation was detected only in AMF-transfected cells and not in controls. This phosphorylation was abrogated by inhibition of PI3K. In conclusion, AMF overexpressing NIH3T3 cells acquired aggressive invasion ability, tumorigenicity and apoptosis resistance via PI3K-mediated activation of Akt/PKB.

Haga et al. (2003) also reported apoptosis protection by AMF using the AMF-transfected HT1080 cells and the Ehrlich cells that originally overexpressed and secreted AMF, both of which were the same as the cell lines that we used. Their experiment also showed that overexpression of AMF contributed to morphological changes and an increase in cell motility. To induce apoptosis, mitomycin $\mathrm{C}$, an apoptosis-inducible anti-cancer drug, was used and AMF overexpressing cells were resistant to this drug. They used a DNA chip to compare the gene expression of AMF-transfected HT1080 with that of MOCK cells and detected some genes that disappeared including caspase-9 and apoptotic protease activating factor 1 (Apaf-1). Interacting with cytochrome c and 2deoxy-ATP, Apaf-1 processes and activates pro-caspase- 9 and then active caspase-9 cleaves and activates procaspase-3, initiating a cascade of apoptosis (Purring-Koch \& McLendon 2000). Haga et al. (2003) were able to detect active caspase-3 in MOCK cells but not in AMFtransfected HT1080 cells. PKC inhibitor GF109203X,
PI3K inhibitor wortmanin and MAPK inhibitor PD98059 were able to recover the expression of Apaf-1 and caspase-9 in the AMF-transfected HT1080 cells; meanwhile, in the Ehrlich cells, only GF109203X was an effective helper of mitomycin-C-induced apoptosis. However, a cocktail of GF109203X, wortmanin and PD98059 induced apoptosis on the Ehrlich cells more effectively than did GF109203X alone.

These two sets of data indicated that AMF plays an important roll in inducing cell survival against the apoptosis signal. However, it remains to be discussed which pathways overexpressed the AMF effect to acquire anti-apoptotic ability. The sensitivity of the inhibitors may be different among the cells or AMF may display different effects on different apoptosis inducers (serum deprivation versus mitomycin-C). In addition, there is a possibility that the increase in PGI enzymatic activity by overexpression of this protein may result in hypermetabolism of glucose which is related to malignant tumors (Warburg 1956, Di Chiro et al. 1982) and affect the apoptosis pathways. The signal pathways with regard to apoptosis resistance induced by AMF overexpression are presented in Fig. 3.

\section{Conclusion}

AMF is a multifunctional protein and recent studies have revealed that, in addition to motility stimulation, this protein plays important roles in the behavior of malignant tumors, such as angiogenesis, ascites accumulation and anti-apoptotic effects. Disrupting AMFR or neutralizing AMF can be considered to be a molecular targeting cancer therapy. Meanwhile, we must remember that the complete block of AMF may be lethal for normal cells because this protein is essential for glycolysis. Romagnoli et al. (2003) reported that antisense against AMF induced apoptosis in normal neuronal cells. Advanced studies with regard to the mechanisms of overexpression and secretion of this protein are needed to block the signals related to malignancy.

\section{Acknowledgement}

This work was supported in part by NIH Grant CA51714 (to A R).

\section{References}

Abe T, Okamura K, Ono M, Kohno K, Mori T, Hori S \& Kuwano M 1993 Induction of vascular endothelial tubular morphogenesis by human glioma cells. A model system for tumor angiogenesis. Journal of Clinical Investigation 92 54-61. 
Akedo H, Shinkai K, Mukai M, Mori Y, Tateishi R, Tanaka K, Yamamoto R \& Morishita T 1986 Interaction of rat ascites hepatoma cells with cultured mesothelial cell layers: a model for tumor invasion. Cancer Research 46 2416-2422.

Albrecht-Buehler G 1977 Phagokinetic tracks of 3T3 cells: parallels between the orientation of track segments and of cellular structures which contain actin or tubulin. Cell 12333 339.

Alessi DR, Andjelkovic M, Caudwell B, Cron P, Morrice N, Cohen P \& Hemmings BA 1996 Mechanism of activation of protein kinase B by insulin and IGF-1. EMBO Journal 15 6541-6551.

Bardelli A, Longati P, Albero D, Goruppi S, Schneider C, Ponzetto C \& Comoglio PM 1996 HGF receptor associates with the anti-apoptotic protein BAG-1 and prevents cell death. EMBO Journal 15 6205-6212.

Baughan MA, Valentine WN, Paglia DE, Ways PO, Simons ER \& DeMarsh QB 1968 Hereditary hemolytic anemia associated with glucosephosphate isomerase (GPI) deficiency - a new enzyme defect of human erythrocytes. Blood 32 236-249.

Baumann M \& Brand K 1988 Purification and characterization of phosphohexose isomerase from human gastrointestinal carcinoma and its potential relationship to neuroleukin. Cancer Research 48 7018-7021.

Baumann M, Kappl A, Lang T, Brand K, Siegfried W \& Paterok E 1990 The diagnostic validity of the serum tumor marker phosphohexose isomerase (PHI) in patients with gastrointestinal, kidney, and breast cancer. Cancer Investigation 8 351-356.

Benlimame N, Le PU \& Nabi IR 1998 Localization of autocrine motility factor receptor to caveolae and clathrin-independent internalization of its ligand to smooth endoplasmic reticulum. Molecular Biology of the Cell 9 1773-1786.

Beutler E, West C, Britton HA, Harris J \& Forman L 1997 Glucosephosphate isomerase (GPI) deficiency mutations associated with hereditary nonspherocytic hemolytic anemia (HNSHA). Blood Cells, Molecules, and Diseases 23 402-409.

Bikfalvi A, Klein S, Pintucci G \& Rifkin DB 1997 Biological roles of fibroblast growth factor-2. Endocrine Reviews 18 26-45.

Boone C Sasaki M \& McKee RW 1965 Characterization of an in vitro strain of Ehrlich-Lettre ascites carcinoma subjected to many periodic mouse passages. Journal of the National Cancer Institute 34 725-740.

Cardone MH, Roy N, Stennicke HR, Salvesen GS, Franke TF, Stanbridge E, Frisch S \& Reed JC 1998 Regulation of cell death protease caspase- 9 by phosphorylation. Science $\mathbf{2 8 2}$ 1318-1321.

Chaput M, Claes V, Portetelle D, Cludts I, Cravador A, Burny A, Gras H \& Tartar A 1988 The neurotrophic factor neuroleukin is $90 \%$ homologous with phosphohexose isomerase. Nature 332 454-455.

Datta SR, Dudek H, Tao X, Masters S, Fu H, Gotoh Y \& Greenberg ME 1997 Akt phosphorylation of BAD couples survival signals to the cell-intrinsic death machinery. Cell 91 231-241.

Descamps S, Toillon RA, Adriaenssens E, Pawlowski V, Cool SM, Nurcombe V, Le Bourhis X, Boilly B, Peyrat JP \& Hondermarck H 2001 Nerve growth factor stimulates proliferation and survival of human breast cancer cells through two distinct signaling pathways. Journal of Biological Chemistry 276 17864-17870.

Di Chiro G, DeLaPaz RL, Brooks RA, Sokoloff L, Kornblith PL, Smith BH, Patronas NJ, Kufta CV, Kessler RM, Johnston GS, Manning RG \& Wolf AP 1982 Glucose utilization of cerebral gliomas measured by $\left[{ }^{18} \mathrm{~F}\right]$ fluorodeoxyglucose and positron emission tomography. Neurology 32 1323-1329.

Dirac-Svejstrup AB, Sumizawa T \& Pfeffer SR 1997 Identification of a GDI displacement factor that releases endosomal Rab GTPases from Rab-GDI. EMBO Journal 16 465-472.

Dunham LJ \& Stewart HL 1953 A survey of transplantable and transmissible animal tumors. Journal of the National Cancer Institue 13 1299-1377.

Dvorak HF, Brown LF, Detmar M \& Dvorak AM 1995 Vascular permeability factor/vascular endothelial growth factor, microvascular hyperpermeability, and angiogenesis. American Journal of Pathology 146 1029-1039.

Faik P, Walker JIH, Redmill AAM \& Morgan MJ 1988 Mouse glucose-6-phosphate isomerase and neuroleukin have identical 3' sequences. Nature 332 455-457.

Fang S, Ferrone M, Yang C, Jensen JP, Tiwari S \& Weissman AM 2001 The tumor autocrine motility factor receptor, gp78, is a ubiquitin protein ligase implicated in degradation from the endoplasmic reticulum. PNAS 98 14422-14427.

Feldman GB, Knapp RC, Order SE \& Hellman S 1972 The role of lymphatic obstruction in the formation of ascites in a murine ovarian carcinoma. Cancer Research 32 1663-1666.

Filella X, Molina R, Jo J, Mas E \& Ballesta AM 1991 Serum phosphohexose isomerase activities in patients with colorectal cancer. Tumour Biology 12 360-367.

Folkman J 1990 What is the evidence that tumors are angiogenesis dependent? Journal of the National Cancer Institute 82 4-6.

Folkman J \& Klagsbrun M 1987 Angiogenic factors. Science 235 442-447.

Folkman J \& Shing Y 1992 Angiogenesis. Journal of Biological Chemistry 267 10931-10934.

Folkman J, Watson K, Ingber D \& Hanahan D 1989 Induction of angiogenesis during the transition from hyperplasia to neoplasia. Nature 339 58-61.

Franke TF, Kaplan DR, Cantley LC \& Toker A 1997 Direct regulation of the Akt proto-oncogene product by phosphatidylinositol-3,4-bisphosphate. Science 275 665-668.

Funasaka T, Haga A, Raz A \& Nagase H 2001 Tumor autocrine motility factor is an angiogenic factor that stimulates endothelial cell motility. Biochemical and Biophysical Research Communications 285 118-128.

Funasaka T, Haga A, Raz A \& Nagase H 2002a Tumor autocrine motility factor induces hyperpermeability of endothelial and mesothelial cells leading to accumulation of ascites fluid. Biochemical and Biophysical Research Communications 293 192-200.

Funasaka T, Haga A, Raz A \& Nagase H $2002 b$ Autocrine motility factor secreted by tumor cells upregulates vascular endothelial growth factor receptor (Flt-1) expression in endothelial cells. International Journal of Cancer 101 217-223. 
Garrison RN, Galloway RH \& Heuser LS 1987 Mechanisms of malignant ascites production. Journal of Surgical Research $\mathbf{4 2}$ $126-132$.

Gildea JJ, Seraj MJ, Oxford G, Harding MA, Hampton GM, Moskaluk CA, Frierson HF, Conaway MR \& Theodorescu D 2002 RhoGDI2 is an invasion and metastasis suppressor gene in human cancer. Cancer Research 62 6418-6423.

Gurney ME, Heinrich SP, Lee MR \& Yin HS $1986 a$ Molecular cloning and expression of neuroleukin, a neurotrophic factor for spinal and sensory neurons. Science 234 566-574.

Gurney ME, Apatoff BR, Spear GT, Baumel MJ, Antel JP, Bania MB \& Reder AT $1986 b$ Neuroleukin: a lymphokine product of lectin-stimulated T cells. Science 234 574-581.

Haga A, Niinaka Y \& Raz A 2000 Phosphohexose isomerase/ autocrine motility factor/neuroleukin/maturation factor is a multifunctional phosphoprotein. Biochimica et Biophysica Acta 1480 235-244.

Haga A, Funasaka T, Niinaka Y, Raz A \& Nagase H 2003 Autocrine motility factor signaling induces tumor apoptotic resistance by regulations Apaf-1 and Caspase-9 apoptosome expression. International Journal of Cancer 107 707-714.

Hall A 1990 The cellular functions of small GTP-binding proteins. Science 249 635-640.

Hall A 1998 Rho GTPases and the actin cytoskeleton. Science 279 509-514.

Harding MA, Arden KC, Gildea JW, Gildea JJ, Perlman EJ, Viars C \& Theodorescu D 2002 Functional genomic comparison of lineage-related human bladder cancer cell lines with differing tumorigenic and metastatic potentials by spectral karyotyping, comparative genomic hybridization, and a novel method of positional expression profiling. Cancer Research 62 6981-6989.

Harrington EA, Bennett MR, Fanidi A \& Evan GI 1994 c-Myc-induced apoptosis in fibroblasts is inhibited by specific cytokines. EMBO Journal 13 3286-3295.

Harrison RA 1974 The detection of hexokinase, glucosephosphate isomerase and phosphoglucomutase activities in polyacrylamide gels after electrophoresis: a novel method using immobilized glucose 6-phosphate dehydrogenase. Analytical Biochemistry 61 500-507.

Kanbe K, Chigira M \& Watanabe H 1994 Effects of protein kinase inhibitors on the cell motility stimulated by autocrine motility factor. Biochimica et Biophysica Acta. 1222 395-399.

Kanno H, Fujii H, Hirono A, Ishida Y, Ohga S, Fukumoto Y, Matsuzawa K, Ogawa S \& Miwa S 1996 Molecular analysis of glucose phosphate isomerase deficiency associated with hereditary hemolytic anemia. Blood 88 2321-2235.

Kanno S, Oda N, Abe M, Terai Y, Ito M, Shitara K, Tabayashi K, Shibuya M \& Sato Y 2000 Roles of two VEGF receptors, Flt-1 and KDR, in the signal transduction of VEGF effects in human vascular endothelial cells. Oncogene 19 2138-2146.

Khwaja A, Rodriguez-Viciana P, Wennstrom S, Warne PH \& Downward J 1997 Matrix adhesion and Ras transformation both activate a phosphoinositide 3-OH kinase and protein kinase B/Akt cellular survival pathway. EMBO Journal 16 2783-2793.

Koch AE, Polverini PJ, Kunkel SL, Harlow LA, DiPietro LA, Elner VM, Elner SG \& Strieter RM 1992 Interleukin-8 as a macrophage-derived mediator of angiogenesis. Science $\mathbf{2 5 8}$ 1798-1801.

Kohn EC, Liotta LA \& Schiffmann E 1990 Autocrine motility factor stimulates a three-fold increase in inositol trisphosphate in human melanoma cells. Biochemical and Biophysical Research Communications 166 757-764.

Kugler W, Breme K, Kugler W, Breme K, Laspe P, Muirhead H, Davies C, Winkler H, Schr-ter W \& Lakomek M 1998 Molecular basis of neurological dysfunction coupled with haemolytic anaemia in human glucose-6-phosphate isomerase (GPI) deficiency. Human Genetics 103 450-454.

Kumar R, Yoneda J, Bucana CD \& Fidler IJ 1998 Regulation of distinct steps of angiogenesis by different angiogenic molecules. International Journal of Oncology 12 749-757.

Le PU, Benlimame N, Lagana A, Raz A \& Nabi IR 2000 Clathrin-mediated endocytosis and recycling of autocrine motility factor receptor to fibronectin fibrils is a limiting factor for NIH-3T3 cell motility. Journal of Cell Science 113 3227-3240.

Leung DW, Cachianes G, Kuang WJ, Goeddel DV \& Ferrara N 1989 Vascular endothelial growth factor is a secreted angiogenic mitogen. Science 246 1306-1309.

Liotta LA, Kleinerman J \& Saidel GM 1974 Quantitative relationships of intravascular tumor cells, tumor vessels, and pulmonary metastases following tumor implantation. Cancer Research 34 997-1004.

Liotta LA, Mandler R, Murano G, Katz DA, Gordon RK, Chiang PK \& Schiffmann E 1986 Tumor cell autocrine motility factor. PNAS 83 3302-3306.

Luo JC, Yamaguchi S, Shinkai A, Shitara K \& Shibuya M 1998 Significant expression of vascular endothelial growth factor/ vascular permeability factor in mouse ascites tumors. Cancer Research 58 2652-2660.

Luo Y, Luo Y, Long JM, Lu C, Chan SL, Spangler EL, Mascarucci P, Raz A, Longo DL, Mattson MP, Ingram DK \& Weng NP 2002 A link between maze learning and hippocampal expression of neuroleukin and its receptor gp78. Journal of Neurochemistry 80 354-361.

Maruo N, Morita I, Shirao M \& Murota S 1992 IL-6 increases endothelial permeability in vitro. Endocrinology 131 710-714.

Matsumoto I, Staub A, Benoist C \& Mathis D 1999 Arthritis provoked by linked $\mathrm{T}$ and $\mathrm{B}$ cell recognition of a glycolytic enzyme. Science 286 1732-1735.

Miles AA \& Miles EM 1952 Vascular reactions to histamine, histamine-liberator and leukotaxine in the skin of guinea-pigs. Journal of Physiology 118 228-257.

Nabi IR \& Raz A 1987 Cell shape modulation alters glycosylation of a metastatic melanoma cell-surface antigen. International Journal of Cancer 40 396-402.

Niinaka Y, Paku S, Haga A, Watanabe H \& Raz A 1998 Expression and secretion of neuroleukin/phosphohexose isomerase/maturation factor as autocrine motility factor by tumor cells. Cancer Research 58 2667-2674.

Nobes CD \& Hall A 1995 Rho, rac, and cdc42 GTPases regulate the assembly of multimolecular focal complexes associated with actin stress fibers, lamellipodia, and filopodia. Cell $\mathbf{8 1}$ 53-62.

Parrizas M, Saltiel AR \& LeRoith D 1997 Insulin-like growth factor 1 inhibits apoptosis using the phosphatidylinositol 
3'-kinase and mitogen-activated protein kinase pathways Journal of Biological Chemistry 272 154-161.

Passaniti A, Taylor RM, Pili R, Guo Y, Long PV, Haney JA, Pauly RR, Grant DS \& Martin GR 1992 A simple, quantitative method for assessing angiogenesis and antiangiogenic agents using reconstituted basement membrane, heparin, and fibroblast growth factor. Laboratory Investigation 67 519-528.

Patel PS, Raval GN, Rawal RM, Patel GH, Balar DB, Shah PM \& Patel DD 1995 Comparison between serum levels of carcinoembryonic antigen, sialic acid and phosphohexose isomerase in lung cancer. Neoplasma 42 271-274.

Purring-Koch C \& McLendon G 2000 Cytochrome c binding to Apaf-1: the effects of dATP and ionic strength. PNAS 97 11928-11931.

Quinn TP, Peters KG, De Vries C, Ferrara N \& Williams LT 1993 Fetal liver kinase 1 is a receptor for vascular endothelial growth factor and is selectively expressed in vascular endothelium. PNAS 90 7533-7537.

Repesh LA 1989 A new in vitro assay for quantitating tumor cell invasion. Invasion Metastasis 9 192-208.

Ridley AJ \& Hall A 1992 The small GTP-binding protein rho regulates the assembly of focal adhesions and actin stress fibers in response to growth factors. Cell 70 389-399.

Ridley AJ, Paterson HF, Johnston CL, Diekmann D \& Hall A 1992 The small GTP-binding protein rac regulates growth factor-induced membrane ruffling. Cell 70 401-410.

Risau W 1997 Mechanisms of angiogenesis. Nature 386 671-674.

Romagnoli A, Oliverio S, Evangelisti C, Iannicola C, Ippolito G \& Piacentini M 2003 Neuroleukin inhibition sensitises neuronal cells to caspase-dependent apoptosis. Biochemical and Biophysical Research Communications 302 448-453.

Scherle P, Behrens T \& Staudt LM 1993 Ly-GDI, a GDPdissociation inhibitor of the RhoA GTP-binding protein, is expressed preferentially in lymphocytes. PNAS $\mathbf{9 0}$ 7568-7572.

Schröter W, Eber SW, Bardosi A, Gahr M, Gabriel M \& Sitzmann FC 1985 Generalised glucosephosphate isomerase (GPI) deficiency causing haemolytic anaemia, neuromuscular symptoms and impairment of granulocytic function: a new syndrome due to a new stable GPI variant with diminished specific activity (GPI Homburg). European Journal of Pediatrics 144 301-305.

Senger DR, Galli SJ, Dvorak AM, Perruzzi CA, Harvey VS \& Dvorak HF 1983 Tumor cells secrete a vascular permeability factor that promotes accumulation of ascites fluid. Science 219 983-985.

Seraj MJ, Harding MA, Gildea JJ, Welch DR \& Theodorescu D 2000 The relationship of BRMS1 and RhoGDI2 gene expression to metastatic potential in lineage related human bladder cancer cell lines. Clinical and Experimental Metastasis 18 519-525.

Shibuya M, Yamaguchi S, Yamane A, Ikeda T, Tojo A, Matsushime H \& Sato M 1990 Nucleotide sequence and expression of a novel human receptor-type tyrosine kinase gene (flt) closely related to the fms family. Oncogene 5 519-524.

Shimizu K, Tani M, Watanabe H, Nagamachi Y, Niinaka Y, Shiroishi T, Ohwada S \& Raz A 1999 The autocrine motility factor receptor gene encodes a novel type of seven transmembrane protein. FEBS Letters 456 295-300.

Silletti S, Watanabe H, Hogan V, Nabi IR \& Raz A 1991 Purification of B16-F1 melanoma autocrine motility factor and its receptor. Cancer Research 51 3507-3511.

Silletti S \& Raz A 1993 Autocrine motility factor is a growth factor. Biochemical and Biophysical Research Communications 194 446-457.

Soker S, Kaefer M, Johnson M, Klagsbrun M, Atala A \& Freeman MR 2001 Vascular endothelial growth factormediated autocrine stimulation of prostate tumor cells coincides with progression to a malignant phenotype. American Journal of Pathology 159 651-659.

Suarez S \& Ballmer-Hofer K 2001 VEGF transiently disrupts gap junctional communication in endothelial cells. Journal of Cell Science 114 1229-1235.

Tanaka N, Haga A, Uemura H, Akiyama H, Funasaka T, Nagase H, Raz A \& Nakamura KT 2002 Inhibition mechanism of cytokine activity of human autocrine motility factor examined by crystal structure analyses and site-directed mutagenesis studies. Journal of Molecular Biology 318 985-997.

Tapper J, Kettunen E, El-Rifai W, Seppala M, Andersson LC \& Knuutila S 2001 Changes in gene expression during progression of ovarian carcinoma. Cancer Genetics and Cytogenetics 128 1-6.

Terman BI, Carrion ME, Kovacs E, Rasmussen BA, Eddy RL \& Shows TB 1991 Identification of a new endothelial cell growth factor receptor tyrosine kinase. Oncogene 6 1677-1683.

Timar J, Silletti S, Bazaz R, Raz A \& Honn KV 1993 Regulation of melanoma-cell motility by the lipoxygenase metabolite 12-(S)-HETE. International Journal of Cancer $\mathbf{5 5}$ 1003-1010.

Torimura T, Ueno T, Kin M, Harada R, Nakamura T, Kawaguchi T, Harada M, Kumashiro R, Watanabe H, Raz A \& Sata M 2001 Autocrine motility factor enhances hepatoma cell invasion across the basement membrane through activation of $\beta 1$ Integrin. Hepatology 34 62-71.

Tsutsumi S, Gupta SK, Hogan V, Collard JG \& Raz A 2002 Activation of small GTPase Rho is required for autocrine motility factor signaling. Cancer Research 62 4484-4490.

Tsutsumi S, Hogan V, Nabi IR \& Raz A 2003 Overexpression of the autocrine motility factor/phosphoglucose isomerase induces transformation and survival of NIH-3T3 fibroblasts. Cancer Research 63 242-249.

de Vries C, Escobedo JA, Ueno H, Houck K, Ferrara N \& Williams LT 1992 The fms-like tyrosine kinase, a receptor for vascular endothelial growth factor. Science 255 989-991.

Warburg O 1956 On the origin of cancer cells. Science $\mathbf{1 2 3}$ 309-314.

Watanabe H, Carmi P, Hogan V, Raz T, Silletti S, Nabi IR \& Raz A 1991a Purification of human tumor cell autocrine motility factor and molecular cloning of its receptor. Journal of Biological Chemistry 266 13442-13448.

Watanabe H, Nabi IR \& Raz A $1991 b$ The relationship between motility factor receptor internalization and the lung 
colonization capacity of murine melanoma cells. Cancer Research 51 2699-2705.

Watanabe H, Kanbe K \& Chigira M 1994 Differential purification of autocrine motility factor derived from a murine protein-free fibrosarcoma. Clinical and Experimental Metastasis 12 155-163.

Watanabe H, Takehana K, Date M, Shinozaki T \& Raz A 1996 Tumor cell autocrine motility factor is the neuroleukin phosphohexose isomerase polypeptide. Cancer Research $\mathbf{5 6}$ 2960-2963.

Xu W, Seiter K, Feldman E, Ahmed T \& Chiao JW 1996 The differentiation and maturation mediator for human myeloid leukemia cells shares homology with neuroleukin or phosphoglucose isomerase. Blood 87 4502-4506.

Yanagawa T, Watanabe H, Takeuchi T, Fujimoto S, Kurihara H \& Takagishi K 2004 Overexpression of autocrine motility factor in metastatic tumor cells: possible association with augmented expression of KIF3A and GDI- $\beta$. Laboratory Investigation 84 513-522.

Zhi J, Sommerfeldt DW, Rubin CT \& Hadjiargyrou M 2001 Differential expression of neuroleukin in osseous tissues and its involvement in mineralization during osteoblast differentiation. Journal of Bone and Mineral Research $\mathbf{1 6}$ 1994-2004. 